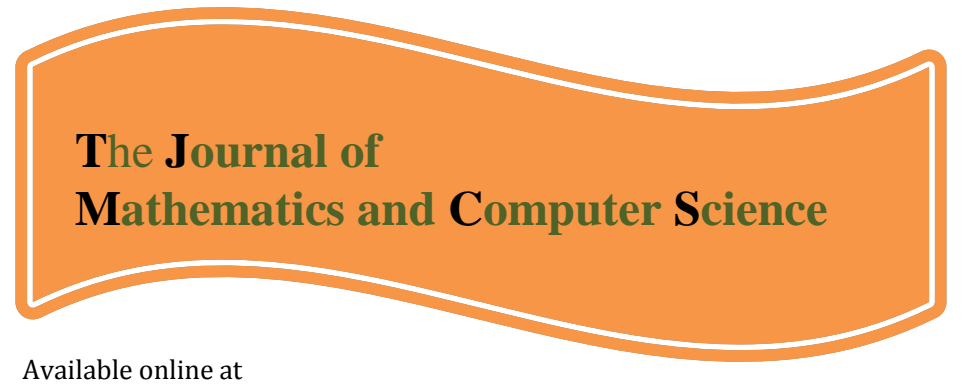

\title{
http://www.TJMCS.com
}

The Journal of Mathematics and Computer Science Vol .4 No.3 (2012) 361-370

\section{Controlling the green- house irrigation system in fuzzy logic method}

\author{
Seyed Kamaleddin Mousavi Mashhadi' ${ }^{1}$ Mojtaba Shokohi nia*2, Mohammad Reza Shokohi nia3 \\ ${ }^{1}$ School of Electrical Engineering , Iran University of Sience and Technology , Tehran, Iran \\ Sk_mousavi@iust.ac.ir \\ 2 Lecturer at the Faculty of Control Engineering of the Islamic Azad University, Damghan Branch \\ mshokohinia@damghaniau.ac.ir \\ ${ }^{3}$ Student of Master's Degree in Control at the Islamic Azad University, Garmsar Branch \\ mshokoohinia@iau-garmsar.ac.ir
}

Received: Feb 2010, Revised: May 2012

Online Publication: Jul 2012

\begin{abstract}
The idea of irrigation is not a new topic and its history refers to pre-historic era. Even the idea of automatic irrigation is not new. At present, there is no efficient automatic irrigation system that can irrigate the plants optimally and use the minimum water in different stage of plant growth(1). Nowadays, computer-monitoring of green-house irrigation systems is very necessary. Many of the common control methods are based on two-state (on/off) control methods and/or proportionate closed-loop control methods which cause increase of energy waste and decrease in productivity. The present research paper provides a solution for an irrigation controller based on fuzzy logic. Firstly, the main problems of irrigation are discussed; then, the physical model for controlling green-house irrigation system is described. Subsequently, the stages of designing a green-house irrigation control system with the aid of fuzzy logic are presented.

This system is able to determine the volume of water required by plants in a specific depth through collecting information from environmental conditions existing inside the green house, the characteristics of the soil, and the type of plants as well as employing famous models of irrigation and water evaporation from the soil surface.
\end{abstract}

Keywords: Fuzzy logic, Green- house, Fuzzy irrigation

\section{Introduction}

Irrigation controller which controls the water running rate and nutrients is considered as the brain of an automatic irrigation system. 
This system monitors the flow of water and fertilizer for plants and as a result of such control, the farmer or gardener achieves the irrigation with maximum yield which is harvesting optimal product with minimum volume of water and nutrients. The shortage of water in Iran is one of the major restricting factors for developing economical operations in the following decades. Unfortunately, in our country optimal water usage as a culture has not found its deserved standing; therefore, achieving a relative equilibrium in water supply and consumption is an essential principle which is not obtained except by creating a comprehensive system of water management. The whole measures taken for supplying water required by agricultural and industrial sectors and cities are mainly in management of water production and supply and little attention has been paid to consumption management.

In new global attitude, water is considered as an economical-social product and the primary need of humans.

Although water is considered as one the renewable resources, its quantity is limited. Water is the major element of all known lives on the earth. Water can not only protect life but also may be a threat for life if it is very abundant or insufficient. Therefore, water is a very precious natural resource that should not be wasted. If a high volume of water is used for irrigation, it causes some problems such as damage by water, erosion, water wastes, and plant diseases; if the irrigation water is insufficient, other different problems such as soil aggregation, etc...occur. The key for proper irrigation is the consumption of optimum volume of water for the appropriate life period of plant (2). In general, the irrigation controllers are divided into two main groups:

\section{Open-loop controllers}

These types of controllers operate on predefined data without any feedback.

The most simple control systems are classified in this group. The operator adjusts the starting time, termination time, pauses, and irrigation period. These parameters are firstly adjusted for the whole periods of the system which are:

How long is the irrigation period?

How many times should the irrigation period be repeated?

How much water or liquid fertilizer is used in this irrigation period?

In this method, no analysis is carried out for being aware whether the optimal volume of water has been consumed or not. This type of controllers is relatively cheap but in most of critical cases they can not operate well. The main factor in irrigation operations is time. Therefore, open-loop controllers employ periodic irrigation method (3). In this irrigation method, appropriate volume of water is supplied to the plant periodically. The experts recommend that in periodic irrigation, the supplied water should be a little more than the need of the plant so that the surplus water can wash the chemicals existing in soil and create a better equilibrium in soil(4).

\section{Closed-loop controller}

Controlling in this type of systems is on the basis of the combination of predefined data and the feedback of controlled factors. This type of controllers has the feedback of the data necessary for determining the required volume of irrigation water. There are several parameters that can affect the volume of water used in irrigation.

Some of these parameters are constant and are among the agricultural characteristics such as the type of plants, type of soil, leaf covering, growth stage, etc..., and some others change and should be measured during irrigation operations. These parameters have physical nature such as temperature, air humidity, radiation intensity, soil moisture, etc... Therefore, when these conditions change, the volume of water used for irrigation should also change [5]. The system described in this research paper employs closed-loop control in which, continuously, the new data about the parameters that change by system are transmitted to the controller such as soil moisture. According to the measures taken by sensors and predefined data such as the type of plant, etc..., the controller decides how much the valve should be opened. The major parameters which determine the irrigation period includes: The growth stage, growth condition (plant height and root depth), leaf covering, and type of soil. Therefore, the input parameters used by the system are: soil moisture, temperature, sun radiation, wind velocity, air humidity, and salinity ( the quantity of soil 
existing in soil) and the output parameters include: turning on/off the valves of water or liquid fertilizer and adjusting their quantity in the combination(6).

\section{Fuzzy-logic intelligent controllers}

Fuzzy logic was emerged by Dr.Lotfizadeh through publishing the article entitled "Fuzzy Series". Since 1965 up now, different concepts and aspects of fuzzy logic have been studied carefully by mathematicians, scientists, and engineers throughout the world (7).

The theory of fuzzy series indicates a concept of uncertainty.

In general, the probability theory was the first tool for analyzing uncertainty which is an accidental process. But all of the uncertainties are not accidental and the theory of the fuzzy series is used for modeling a part of uncertainty which is related to the ambiguity and insufficiency of information. The theory of the series considers difference between the elements that are the members of a series and the ones that are not. The most essential principle of fuzzy is the fact that the membership function $\mu$ can have a value between zero and one.

The general structure of the fuzzy logic controller is shown in Figure 1(8).

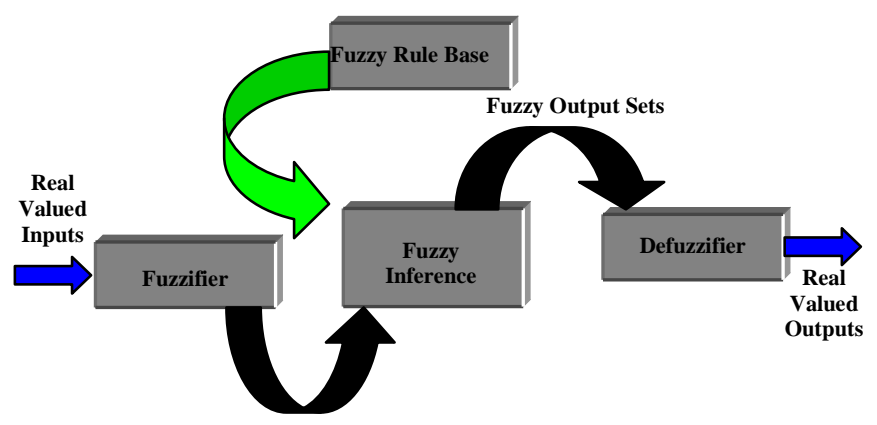

Figure 1. The structure of fuzzy controller

\section{Fuzzy Process}

Fuzzy is a process that writes the inputs of fuzzy control in their membership value in fuzzy functions.

\section{The base of fuzzy rules}

On the basis of the fuzzy control attitude, the rules of fuzzy base are in if and then form. The base of fuzzy rules includes a series of lingual rules which are extractable from the any of the following resources by using experts' information:

- Physical rules governing dynamic equations of the system

- Data from existing controllers

- Experimental knowledge obtained from the expert and experienced individuals. If the expert's knowledge is employed, there is no need for mathematical model of the system and this is one of the great advantages of fuzzy systems.

Designing of fuzzy irrigation controller

Figure 2 shows the diagram block from the whole system. As you see, the control system is composed of three major parts. 


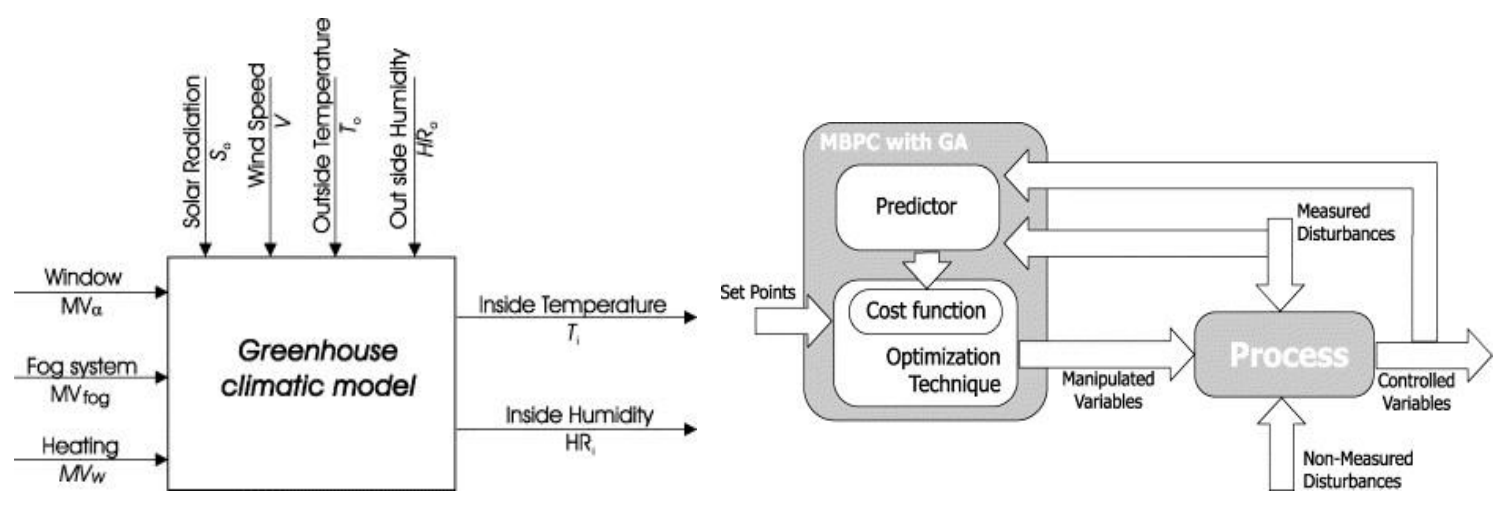

Figure 2. The diagram block of irrigation control system

1.Configuration Stage: In this section, the operator chooses one from predetermined (constant) and/or non-predetermined method. The output of this stage is the rate of optimal soil moisture so that the product can continue its proper growth.

2. Soil evaporation model: At this section, the rate of water flow changes into actual soil moisture.

3. Control stage: In this stage, the optimal soil moisture is measured and compared with the actual moisture of the soil. After such comparison, a dynamic decision making calculates the volume of water that should be added to the soil.

\section{Configuration Stage:}

For modeling the optimal soil moisture, firstly the required volume of water is extracted with regard to the type of plant, type of soil, and growth period; then, with consideration to the temperature, air humidity, wind velocity, salinity (quantity of salt existing in soil), and sun radiation, the optimal soil moisture is calculated the procedure of which will be different for any plant, growth period, and type of soil. The input variables in this stage are:

Temperature: This stage shows the effect of sun on plant humidity. In other words, as the temperature increases, the rate of evaporation and transpiration of the soil and plant is enhanced and vice-versa. For modeling the temperature, a continuous signal which is usually as a sinusoidal wave is used that simulates the variations of day and night temperatures. But in certain moments, there may be sudden changes. For this purpose, a sinusoidal wave with the amplitude of 5 centigrade degrees, the constant deviation of 30 centigrade degrees, and frequency of 0.2618 radian/h was used(6). This frequency has been measured for 24 hours. This model creates a wave between maximum and minimum values, although the temperatures of every day may be simulated by changing these figures.

\section{Air humidity:}

This variable shows the effect of air humidity on soil moisture. For achieving this, a sinusoidal wave with the amplitude of $10 \%$, the constant deviation of $60 \%$, and frequency of 0.2618 radian/ h was used.

\section{Wind velocity:}

This variable shows the effect of air flow on soil moisture. For this purpose, a sinusoidal wave with the amplitude of 1 , the constant deviation of $2.5 \mathrm{~km} / \mathrm{h}$ and frequency of $0.2618 \mathrm{radian} / \mathrm{h}$ was used (6).

\section{Sun radiation:}

There is a state named as light sensor for sun radiation in the model designed for soil. If the state is zero, the state of automatic models is employed and if it is one the made models are used. For 
achieving this, a sinusoidal wave with the amplitude of 1 and constant deviation of $40 \mathrm{Cal} / \mathrm{cm} 2$ was used.

Salinity (quantity of salt existing in soil): The tolerance of soil against salinity not only is completely different among various species but it changes in any plant and under any environmental conditions. Many of the factors associated with plant, soil, water, and atmosphere are mixed with each other and influence the resistance of any plant to salinity. For this, a sinusoidal wave with an amplitude of 1 and constant deviation of 10 Deci-Siemens $/ \mathrm{m}$. was used.

All of these five input parameters are defined as the fuzzy variables. The reason for determining these five variables as the fuzzy variables is embedded in the nature of the issue and relevant parameters. Firstly, it should be noted that irrigation does not require accurate measurement and an accurate model may be very complicated and expensive; secondly, the variables involved in the decision making process are naturally fuzzy, i.e., the agricultural products do not require an accurate quantity of humidity for growth. There is the amplitude of acceptable water quantity for irrigation in order to growing healthy products; fuzzy control can provide that in a simple method. Therefore, fuzzy variables can describe better the irrigation model compared with the classic model. For example, Figure 3, shows the membership functions associated with fuzzy variable temperature. Here, the very cold function is emphasized. As we see, this variable is defined in a fuzzy method and emphasizes that the temperature of -10 to -5 is certainly very cold; while -5 to 0 also is very cold but to a less extent. The output variable in this stage is optimal soil moisture that is the input of the next stage.

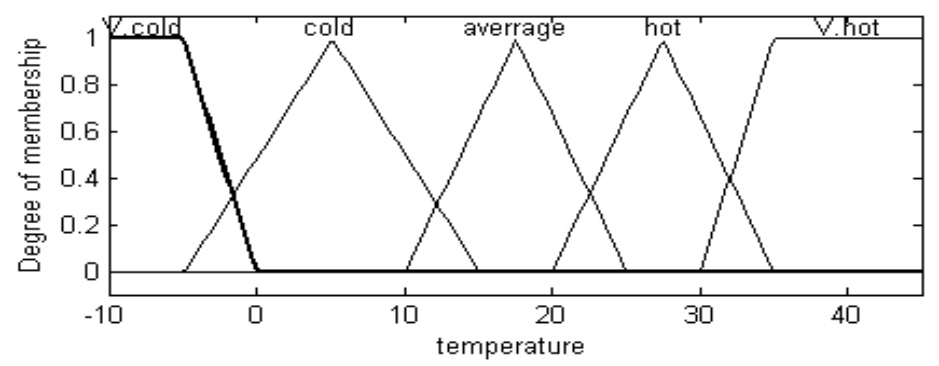

Figure 3: The membership functions associated with fuzzy variable temperature

Soil evaporation model: After creating the optimal quantity of soil moisture, a loop control mechanism should be performed so that the actual quantity of soil moisture is obtained. This system produces a numerical system that is interpreted as follows:

"How much water should be added to the soil?". This is the input figure of soil stage that shows the earth transmission function.

The evaporation and transpiration of earth are considered in the model presented in this article and the actual soil moisture is shown with regard to the quantity of water added to the soil. This model is a first-grade linear invariable system the transmission function of which is $a /(s+b)$. This model means that the soil moisture of permanent state is gained from $\mathrm{Xa} / \mathrm{b}$ for turning on $\mathrm{X} \%$ of valve. In addition to this, the ratio of time constant of the soil moisture to the rate of turning on the valve is $1 / \mathrm{b}$ of time units. This model is close to the conventional model of soil evaporation and other green-house heating models(6).

The $\mathrm{a}$ and $\mathrm{b}$ parameters may be predetermined constants or functions of external parameters such as heat, radiation, etc... Figure 4 shows the general diagram of soil model in which a and $\mathrm{b}$ are the predetermined constants that are used for simulating soil behavior. 


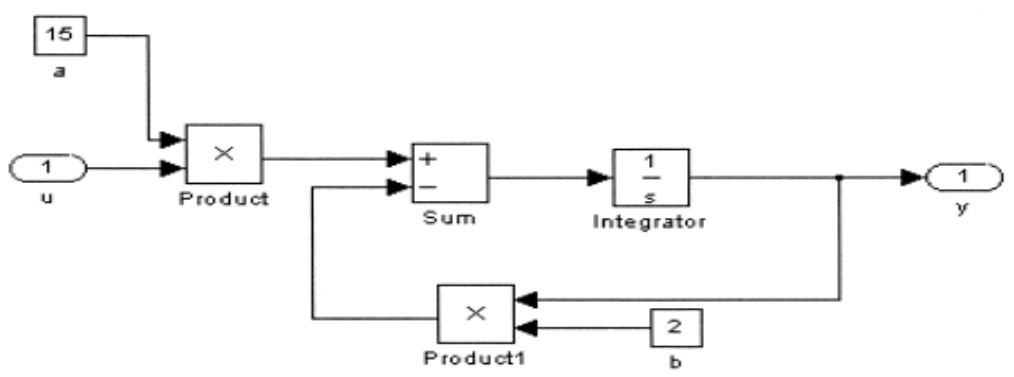

Figure 4: General diagram of soil model

Control Stage: In this stage, the actual soil moisture is deducted from the optimal soil moisture. In other words, the difference of these two values is obtained and it is tried to incline to zero as much as possible. The output of this stage is the state of water control valve and the volume of water that should be added to soil so that the error value leans to zero. Diagram block of fuzzy controller is shown in Figure 5. As you see in the figure, the controller has merely one input signal (the difference between the quantities of desired and actual moisture of soil) and one output signal (control of the state of valve). This causes that the system to be very simple. The input and output quantities have been defined within the ranges of -100 and 100 as well as $0-100$ respectively. The controller can determine the optimal extent of valve function.

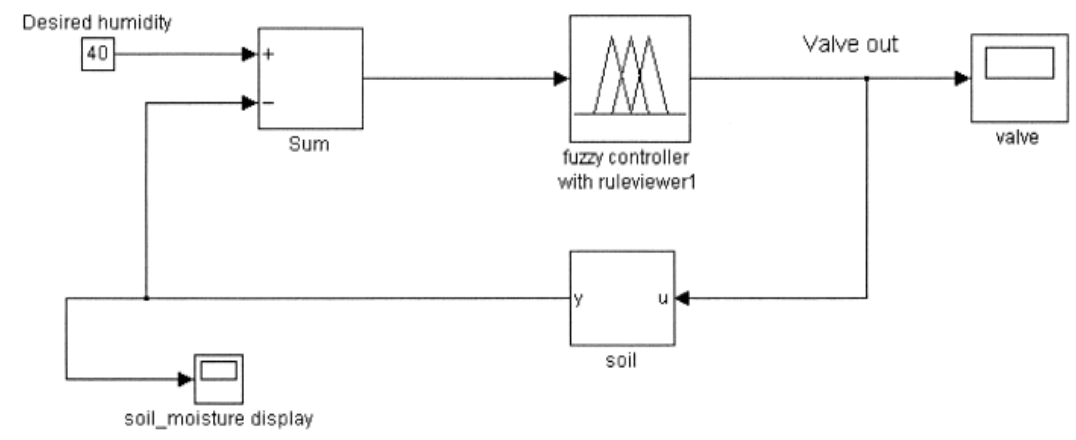

Figure 5. The fuzzy controller model with soil model

The input membership function of fuzzy controller that is, indeed, the difference of optimal and actual moisture of soil is shown in Figure 6. The laws of controller are very simple and there are only five laws which are shown in Figure 7. The simulation examples are presented in Table 1. As you see, when soil is humid (negative difference), the output of valve is zero(the valve is turned off). Immediately, when soil becomes drier, the valve turns on more.

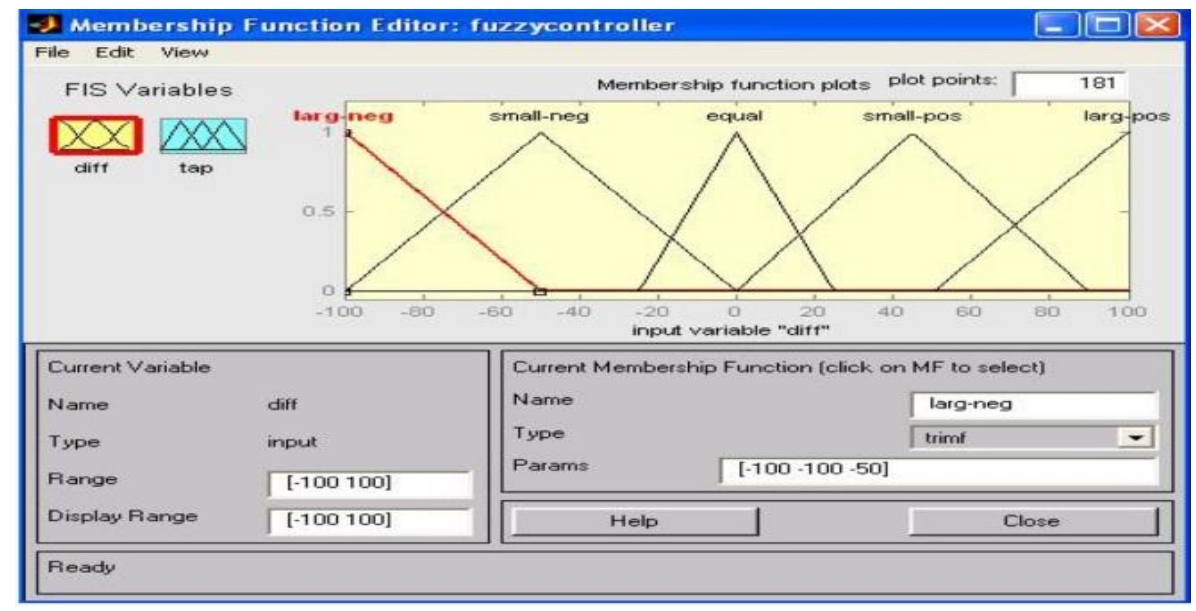

Figure 6 . The membership function for input variable of fuzzy controller. 


\begin{tabular}{llcccc}
\hline Input (diff) & Output (valve) & Input (diff) & Output (valve) & Input (diff) & Output (valve) \\
\hline-100 & 0 & 0 & 0 & 50 & 13.4202 \\
-90 & 0 & 5 & 7.4681 & 60 & 22.8184 \\
-80 & 0 & 10 & 11.1642 & 70 & 32.7705 \\
-70 & 0 & 20 & 12.4075 & 80 & 38.9501 \\
-20 & 0 & 30 & 12.9641 & 90 & 44.6889 \\
-10 & 0 & 40 & 13.3180 & 100 & 47.3813 \\
\hline
\end{tabular}

Table 1

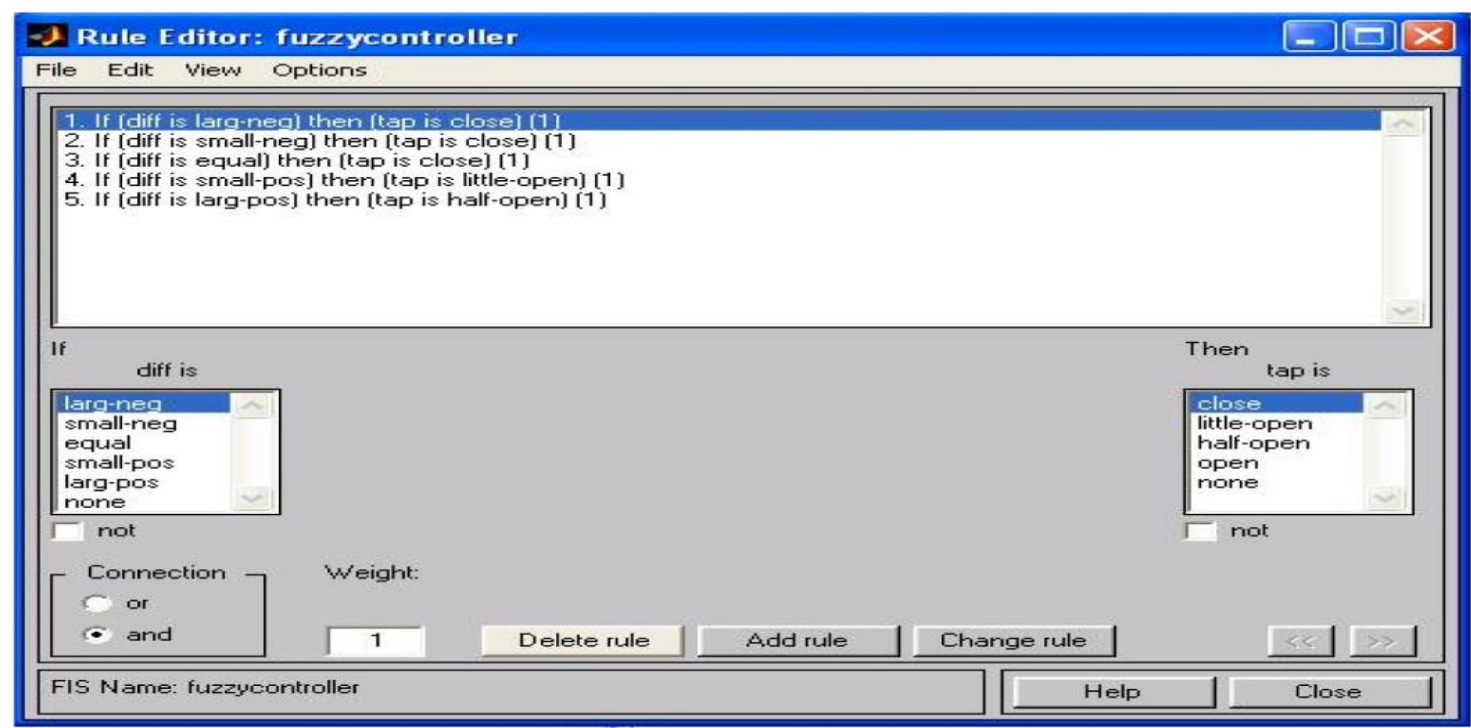

Figure 7: Windows for fuzzy controller laws

System structure: A basic concept in this system is standardization of its function systems; indeed, any part of the irrigation control system may be used in a separate system. This concept is shown in the model of irrigation control system in Figure 8. As you see in the figure, in any stage the manual input configuration has been inserted which makes the operation able to apply his/her desired moisture to the system. Otherwise, the optimal soil moisture will be applied to the system automatically.

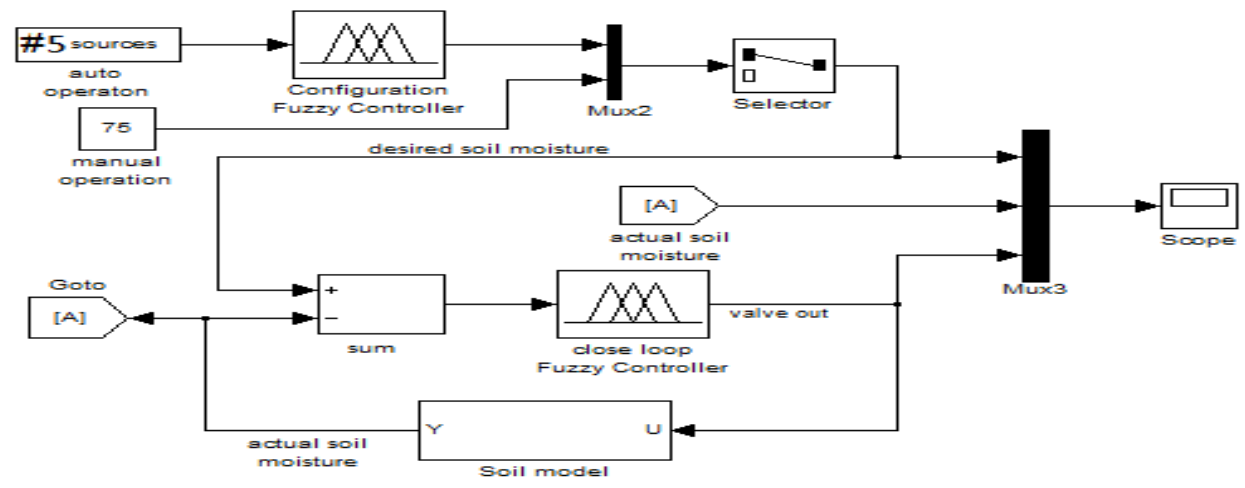

Figure 8. Model of irrigation control system

The model of input resources is also shown in Figure 9. 


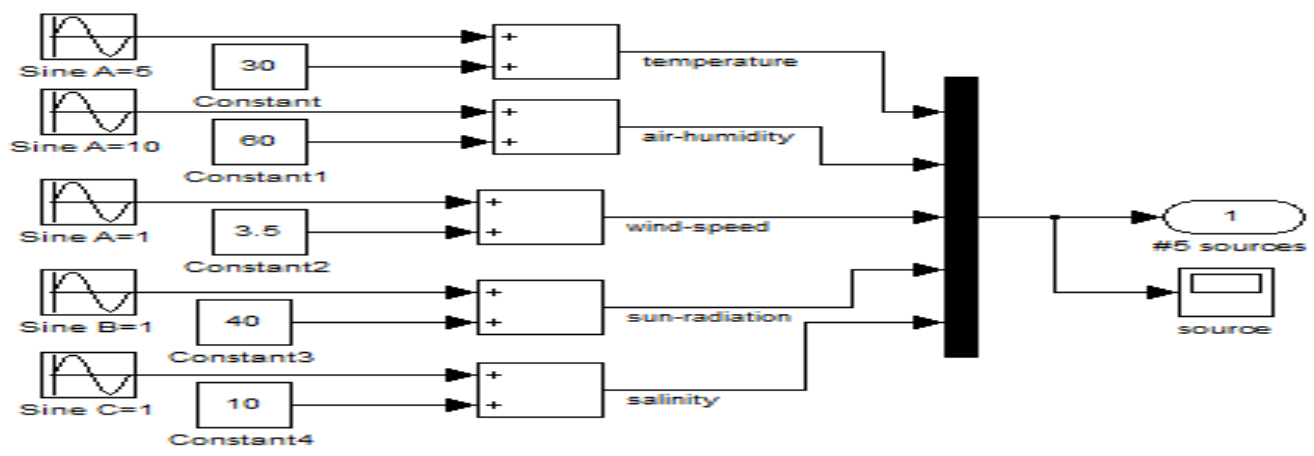

Figure 9. Input resources model

\section{The quadratic regression equation gained on the basis of the results of applying fuzzy control}

For finding the relation between the independent variable $\mathrm{X}$ and the dependent variable $\mathrm{Y}$, firstly, a stochastic sample from the target population is collected. In other words, for the values of X1, $\mathrm{X} 2, \ldots . . \mathrm{Xn}$ from the independent variable $\mathrm{X}$, the values related to the dependent variable $\mathrm{Y}$ are measured. Assume that these measured values of the dependent variable $Y$ are y1, y2,....yn. Therefore, the stochastic sample is pairs of $(\mathrm{X} 1, \mathrm{Y} 1)(\mathrm{X} 2, \mathrm{Y} 2) \ldots . . .(\mathrm{Xn}, \mathrm{Yn})$ the observed values of which are $(\mathrm{x} 1, \mathrm{y} 1)(\mathrm{x} 2, \mathrm{y} 2) \ldots . . .(\mathrm{xn}, \mathrm{yn})$. In order to find the relation between $\mathrm{x}, \mathrm{Y}$, firstly, these observations that are as points in the plate are drawn in coordinates system which is called scatter diagram. In general, if the value of variable $\mathrm{Y}$ is to be predicted from the value of the variable $\mathrm{X}$, a relation between $\mathrm{x}$.Y should be available. This relation is a predicting equation named as the regression equation of $Y$ over $X$.

According to the data obtained from Table 1, the following quadratic regression equation is gained with the aid of the data resulted from applying fuzzy control the diagram of which is shown in Figure 10 .

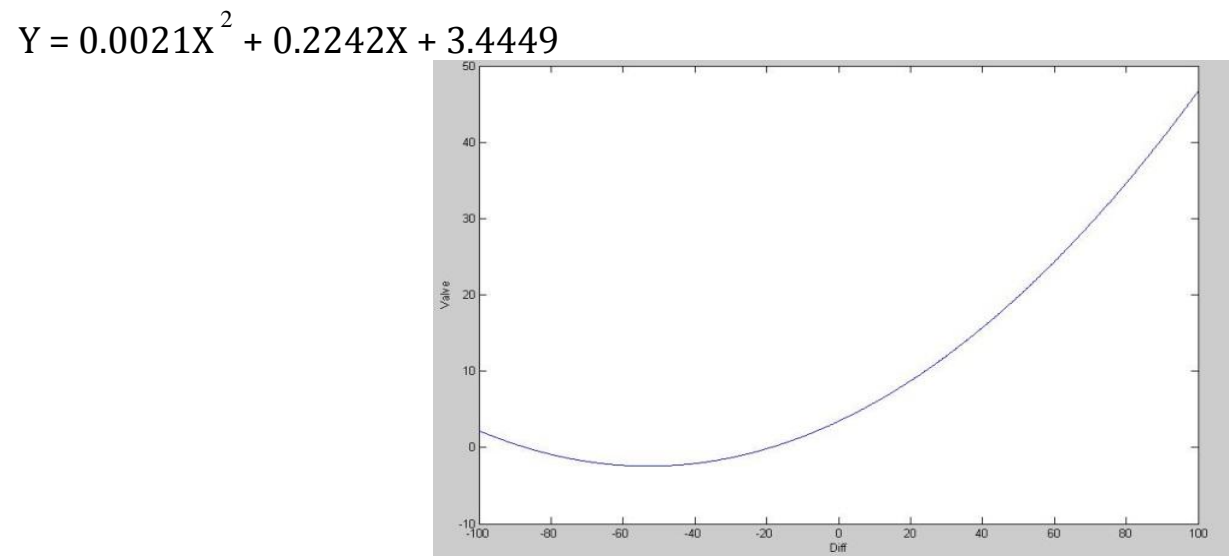

Figure 10:The diagram of quadratic equation

Scatter diagram of quadratic regression equations obtained on the basis of two series of data:

1) With the aid of actual data $\mathrm{Y}=0.002 \mathrm{X}^{2}+0.2355 \mathrm{X}+5.5584$

2) With the help of the data resulted from applying fuzzy control

$\mathrm{Y}=0.0021 \mathrm{X}^{2}+0.2242 \mathrm{X}+3.4449$

Which are shown in Figure 11. 


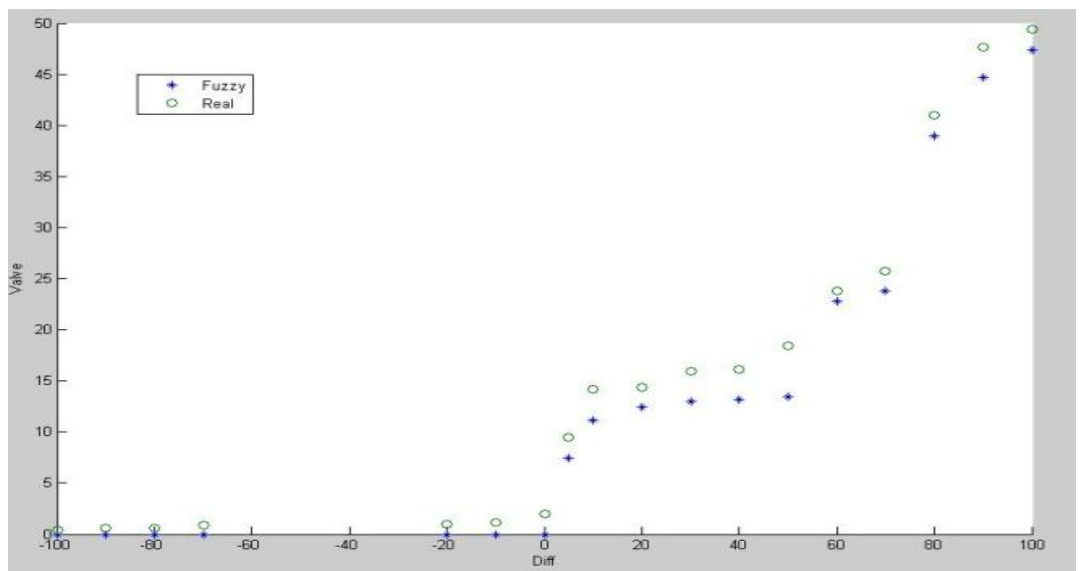

Figure 11. Scatter diagram

As you see in scatter diagram, the designed controller gives us good and acceptable responses and the actual data confirms the responses gained by this method and after doing required calculations which is very optimal from engineering point of view.

Results \& Discussions:

The results of simulation are shown graphically in Figures 12 and 13. In this figure, the diagrams specified with pink and yellow indicate the values of optimal and actual moisture of soil respectively. It should be noted that turning on/off the value and the rate of valve opening are demonstrated with green.

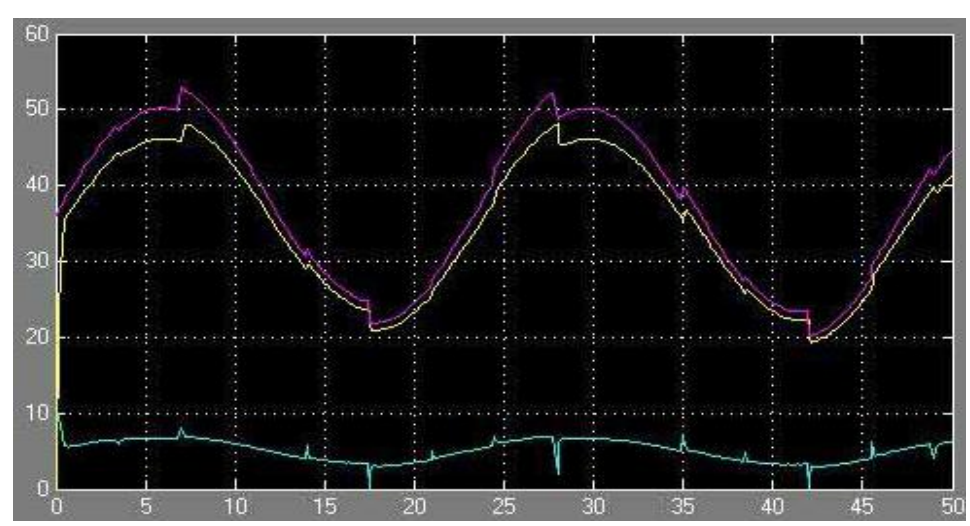

Figure 12. The results of simulation of fuzzy control system

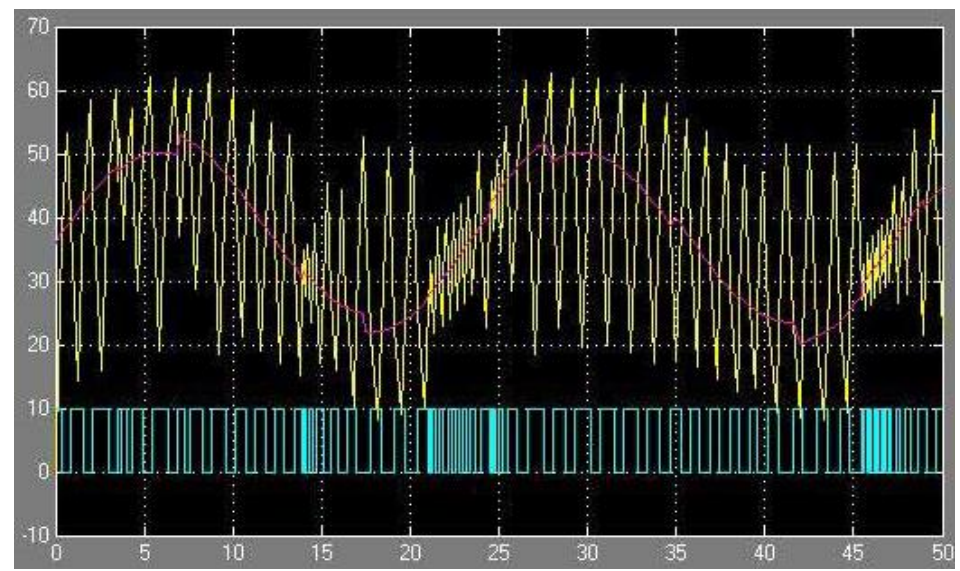

Figure 13. The results of simulation of ON/OFF control system 


\section{There are several important points extractable from the simulation results:}

1. In fuzzy control system, the actual moisture of soil follows the optimal moisture during the simulation period and has no fluctuations similar to ON/OFF systems.

2. In fuzzy control system, the difference between actual and optimal moisture of soil(error) is logical and completely consistent and constant (about 23\%). This indicate that irrigation control is stable.

3. In fuzzy control system, the rate of opening and closing valve is much lower than ON/OFF control system the result of which is less energy consumption and deprecation. While saving in water consumption, this system prevents from water stresses in soil and plant.

4. In fuzzy control system, input production models give the opportunity to the operator to create very different inputs. Therefore, controller may operate in any climatic conditions.

\section{Conclusion}

In the present research paper, the irrigation control system equipped with fuzzy controller and ON/Off control system is described. Firstly, the general structure and its elements are explained; then, some examples indicate the system operates and is stable within appropriate limits the results obtained from regression also confirms this claim. Finally, the fuzzy control systems in addition to having low cost compared with ON/OFF systems, benefits from potentials such as saving water and energy consumption, reducing the depreciation of the parts of control system, and preventing water stresses in soil and plant.

Thus, employing this control system is very useful for all agricultural operations.

\section{References:}

[1] Reuter D. C. and R. S. Everett, 2000, Control theory and applications: neural-fuzzy controller for lawn irrigation

[2] Evans R., Sneed R.E. and D.K. Cassel, 2006. Irrigation scheduling to improve water and energy use efficiencies, North Carolina Cooperative extension Service (AG 452-4).

[3] Burman R. and L.O. Pochop, 2004. Evaporation evapotranspiration and climatic data. Elsevier,Amsterdam

[4] Or D., 2005. Soil water sensors placement and interpretation for drip irrigation management in heterogeneous soils. In: Proceeding of 5th International Microirrigation Congress, 214-222.

[5] Ioslovich I., Gutman P. and I. Seginer, 2006. A non linear optimal greenhouse control problemwith heating and ventilation, Optimal Control applications and methods, 17: 157-169

[6]Bahat M., Inbar G., Yaniv O. and M. Schneider, 2000. A fuzzy irrigation controller system. Engineering Applications of Artificial Intelligence 13: 137-145

[7] Alizadeh, Amin,2006, The relation of water, soil, and plant, published by Imam Reza University, Mashhad

[8] Vang Lee, fuzzy systems and fuzzy control,2006, translated by Teshnehlab, Mohammad, Saffarpour, Nima, Afyouni, Daryoush, published by Khajeh Nasir Toosi University of Technology.

[9] Kazo Tanaka, An introduction to fuzzy logic for its practical applications, translated by Kamyad Vahidian, Ali and Reza, Tareghian, Hamed, Publication No.327 of Ferdowsi University of Mashhad, Spring 2004 